\title{
Monitoring open-ocean deep convection from space
}

\author{
Marine Herrmann, ${ }^{1}$ Jérome Bouffard, ${ }^{2}$ and Karine Béranger ${ }^{3}$ \\ Received 22 October 2008; revised 6 December 2008; accepted 24 December 2008; published 7 February 2009.
}

[1] Deep convection (DC) is a key-process of the oceanic circulation, costly to monitor in situ and under the influence of climate change. Our study is a first step toward monitoring DC from space: we investigate the feasibility of observing its variability using improved satellite altimetry. An oceanic simulation of the Mediterranean circulation was performed for the 1999-2007 period. DC interannual variability is realistically modelled, and the sea surface elevation (SSE) is in agreement with altimetry data. Numerical results show a strong correlation between the annual DC characteristics and the winter SSE. From that, we propose a method to monitor DC interannual variability and long term evolution using altimetry data. Our method, applied to the longest available altimetry series, represents correctly the interannual variability of DC in the Northwestern Mediterranean between 1994 and 2007. Citation: Herrmann, M., J. Bouffard, and K. Béranger (2009), Monitoring open-ocean deep convection from space, Geophys. Res. Lett., 36, L03606, doi:10.1029/2008GL036422.

\section{Introduction}

[2] Open-ocean deep convection (DC) is a key process of the global thermohaline oceanic circulation, at the origin of deep water formation in the world's oceans. It occurs in a few regions, including the Northwestern Mediterranean Sea (NWMS), where it plays an important role in the functioning of marine ecosystems [Lévy et al., 1998]. Because of its sensitivity to atmospheric conditions, it is associated with a high interannual variability [Mertens and Schott, 1998], and may be strongly influenced by climate change [Somot et al., 2006]. Part of the Western Mediterranean Deep Water (WMDW) formed by DC in the NWMS flows in the Atlantic Ocean through the Gibraltar Strait, and may affect the global thermohaline circulation through the impact of the Mediterranean Outflow Water on North Atlantic DC [Reid, 1979]. Indeed, [Rixen et al., 2005] suggested that the WMDW may be a valuable new proxy for estimating the variability of the temperature of the North Atlantic Ocean. Monitoring DC is therefore crucial, however direct in situ monitoring requires a huge investment and realistically can only provide limited temporal and spatial coverage.

[3] In this framework, we investigate the feasibility of monitoring the interannual variability and long term evolution of DC using improved satellite altimetry. We first analyse a high-resolution oceanic numerical simulation to

\footnotetext{
${ }^{1}$ Centre National de Recherches Météorologiques, Météo-France, CNRS, Toulouse, France.

${ }^{2}$ Laboratoire d'Etudes en Géophysique et Océanographie Spatiales, Université de Toulouse, CNRS, Toulouse, France.

${ }^{3}$ Laboratoire d'Océanographie et du Climat: Expérimentations et Approches Numériques, Ecole Nationale Supérieure des Techniques Avancées, Université Paris 6, CNRS, Paris, France.
}

Copyright 2009 by the American Geophysical Union. 0094-8276/09/2008GL036422 assess its ability to represent correctly NWMS winter oceanic circulation and its variability. The numerical results are then used to determine the relationship between the sea surface elevation $(S S E)$ and the DC variability and to build a monitoring method for DC based on altimetry. Finally, we test our method by applying it to the longest available altimetry dataset in the NWMS.

\section{Tools and Data}

\subsection{Model}

[4] The Mediterranean model MED16 [Béranger et al., 2005] is a regional version of the primitive-equation numerical model Ocean PArallel [Madec et al., 1998]. This rigid lid model extends from $11^{\circ} \mathrm{W}$ to $36^{\circ} \mathrm{E}$ and $30^{\circ} \mathrm{N}$ to $46^{\circ} \mathrm{N}$, with a $1 / 16^{\circ}$ horizontal resolution and 43 vertical levels on a stretched grid. Here we use the simulation described by $\mathrm{K}$. Béranger et al. (Effects of atmospheric forcing on deep water formation modelling in the Mediterranean sea, manuscript in preparation, 2009). The model is forced at the surface by daily atmospheric fields using the air-sea parameterizations detailed by Béranger et al. [2005]. During the spin-up period (January 1987-February 1998) the model was forced by ECMWF reanalysis ERA40 fields [Uppala et al., 2005], with horizontal resolution of $1.125^{\circ}$. The model was then forced until October 2007 by ECMWF analysis fields, with a resolution of $0.5^{\circ}$ since March 1999 and $0.2^{\circ}$ since January 2007. Atmospheric fluxes with high spatial resolution $\left(<\sim 0.55^{\circ}\right)$ are required to correctly represent DC in the NWMS [Herrmann and Somot, 2008]. Here, we analyse the April 1998-October 2007 period (9 winters).

\subsection{Altimetry Dataset}

[5] New processing software dedicated to coastal ocean applications were developed, based on Geophysical Data Records provided by operational centers at a rate of $10 \mathrm{~Hz}$ (Topex/Poseidon) and $20 \mathrm{~Hz}$ (Jason 1) and sub-sampled every $2 \mathrm{~km}$ along a fixed reference ground track. In addition to standard procedures for large-scale error reduction, innovations are introduced for the estimation and validation of sea level anomaly (SLA), concerning the high frequency dealiasing of the signal and new quality-control procedures detailed by Bouffard et al. [2008]. This method avoids the systematic rejections of coastal data and allows the recovery of all SLA that exhibit a physical significance. The result is a high resolution satellite dataset with better coverage and quality over the NWMS than the classical altimetry products.

\section{Modelling of DC in the NWMS for the 1999-2007 Period}

\subsection{Interannual Variability of DC}

[6] The mixed layer depth, $M L D$, diagnosed in the model as the depth at which the level of turbulent kinetic energy 
undergoes a sharp decrease with depth, is a good indicator of the depth reached by winter convection [Blanke and Delecluse, 1993]. Figure 1a shows the map of the maximum MLD over the 1999-2007 period in the NWMS. The area where DC occurs can be identified as the region where the mixed layer is significantly deep, i.e., extends below the layer of Ligurian Intermediate Water (LIW) (MLD $>\sim 500 \mathrm{~m})$. The DC area, centered around $\left[5^{\circ} \mathrm{E}, 42^{\circ} \mathrm{N}\right]$, is in agreement with reported observations [Marshall and Schott, 1999]. We define GoL (Gulf of Lions) as the box that covers the DC area entirely (see Figure 1a). We examine the interannual variability of DC by computing at each time step the maximum $M L D$ over the GoL, $D$, and the volume $V$ of deep water (DW) over the GoL (Figure 1e). $V$ corresponds to the mixed layer volume over the area where the $M L D$ exceeds $500 \mathrm{~m}: V(t)=\iint_{(x, y) \in G o L / M L D(x, y, t)>500 \mathrm{~m}} M L D(x, y$, $t) d x d y$. Dividing the yearly maximum of $V$ by the number of seconds in one year gives the yearly rate of DW formation $\tau_{D W}$ [Castellari et al., 2000]. $\tau_{D W}$ and $D_{\max }$, the yearly maximum depth of $D$, are reported in Table $\mathrm{S} 1^{1}$.

[7] In agreement with previous observations made before 1994 [Mertens and Schott, 1998], DC intensity shows strong interannual variability, including a year without convection (2007: $D_{\max }<220 \mathrm{~m}, \tau_{D W}=0 \mathrm{~Sv}$ ), a year with bottom convection (2005: $D_{\max }>2000 \mathrm{~m}, \tau_{D W}=1.28 \mathrm{~Sv}$ ), and intermediate cases $(1999-2004,2006)$. It is rather delicate to validate values of $\tau_{D W}$ due to the difficulty of measuring it experimentally. However, values computed here $(0-1.3 \mathrm{~Sv}$; Table S1) are in the range reported in the literature, obtained from models or in situ data $(0.0-2.4 \mathrm{~Sv}$ [Tziperman and Speer, 1994; Castellari et al., 2000; Herrmann et al., 2008; Schroeder et al., 2008]). Between 1999 and 2006, DC occurs during the January-March period (Figure 1e), in agreement with the observed period of DC [Mertens and Schott, 1998].

[8] Although it is difficult to validate the full cycle of interannual variability of DC, the observed extreme years of DC are well captured by the model. Previous in situ observations described winter 2005 as exceptionally strong from the point of view of DC [Schroeder et al., 2008]. Winters 1999 and 2006 were also stronger than the average [Petrenko, 2003; Schroeder et al., 2008]. The absence of DC in the model for winter 2007 is also confirmed by the observations: vertical sections of water characteristics measured by gliders (MERSEA and DOCONUG projects) and published on the European Gliders Observatories website (https://www.locean-ipsl.upmc.fr/gliders/EGO) confirm that no convection occurred.

[9] Daily satellite sea surface temperature (SST) data [Guarracino et al., 2008] are also useful to validate the interannual variability of the modelled surface characteristics during the convection period. We compare the evolution between 1999 and 2007 of the observed and modelled SST averaged over the GoL between February and midMarch (see Figure S1): we obtain a modelled mean value of $13.11^{\circ} \mathrm{C}$ compared with an observed value of $13.10^{\circ} \mathrm{C}$, with a modelled standard deviation of $0.30^{\circ} \mathrm{C}$ compared with an observed value of $0.28^{\circ} \mathrm{C}$. The correlation coefficient between the model and the observations is equal to 0.89

\footnotetext{
${ }^{1}$ Auxiliary materials are available in the HTML. doi:10.1029/ 2008 GL036422.
}

(significant level SL $>0.999$ ). The model reproduces realistically the interannual variability of $S S T$ during the period and in the region of DC. Note that we do not obtain any significant correlation between the convection characteristics $\left(D_{\max }, V_{\max }, \tau_{D W}\right)$ and the $S S T$ in the model, suggesting that SST data can not be used to monitor DC.

[10] The years of strong, resp. weak convection should correspond to cold, resp. warm winters. The correlation coefficient between $\tau_{D W}$ and the net average heat loss between November and February over the GoL computed from the NCEP reanaysis dataset [Kalnay et al., 1996], $Q_{N D J F}$, is indeed equal to 0.80 ( $\mathrm{SL}>0.990$ ) for the 1999 2007 period.

\subsection{Deep Water Characteristics}

[11] We have seen that the model reproduces correctly the values and interannual variability of winter SST in the convection region. The yearly characteristics of DW formed $\left(T_{D W}, S_{D W}\right.$ and $\left.\rho_{D W}\right)$ are determined for each winter by examining the characteristics of the densest surface water present in the GoL at points where the $M L D>500 \mathrm{~m}$ (Table S1). For years when DW is formed (1999 to 2006), $\rho_{D W}$ logically increases with $\tau_{D W}$, i.e., with the mean depth reached by the whole mixed volume. For the years when the mixed layer extends significantly below the LIW (2000, 2001, 2003, 2005 and 2006), the modelled mixed layer characteristics are in agreement with the observed values of classical WMDW $\left(12.8-13.0^{\circ} \mathrm{C}, 38.44-38.49\right.$ psu, $29.09-$ $29.11 \mathrm{~kg} . \mathrm{m}^{-3}$ vs. $12.8-12.9^{\circ} \mathrm{C}, 38.43-38.48 \mathrm{psu}, 29.09-$ $29.12 \mathrm{~kg} . \mathrm{m}^{-3}$ [Smith et al., 2008; Schroeder et al., 2008]). In 1999 , the DW is slightly saltier (38.51 psu) and warmer $\left(13.1^{\circ} \mathrm{C}\right)$. During the spin-up period $(1987-1998)$ no convection occurred in the NWMS, the salty and warm LIW layer has not been mixed over the water column and remains strongly present when convection occurs for the first time in winter 1999. After 1999, the LIW layer is mixed every year by the convection and is not so marked. The proportion of LIW in the DW formed in 1999 is therefore larger, explaining its higher temperature and salinity.

[12] Comparisons between the model results, available data and previous observational and modelling studies shows that the model reproduces correctly the winter oceanic circulation in the NWMS for the 1999-2007 period. In particular, it represents realistically the interannual variability of DC intensity and DW characteristics.

\section{From Altimetry to Deep Convection}

[13] Two main questions need to be answered in order to establish a method to monitor DC using altimetry data. First, is it possible to link the variability of the DC with the SSE? Second, are we able to measure the fine-scale $S S E$ from space accurately enough to monitor the DC?

\subsection{Validation of the Modelled Sea Surface Elevation in Winter}

[14] The cyclonic circulation in the NWMS, correctly reproduced by the model (as seen on Figure 1b which shows the $S S E$ averaged over $1999-2007, \overline{S S E}$ ) is activated in winter by the convection that occurs in the center of the gyre [Herrmann et al., 2008]. This dynamic effect induces a lowering of the surface in the DC area. Steric effect also 

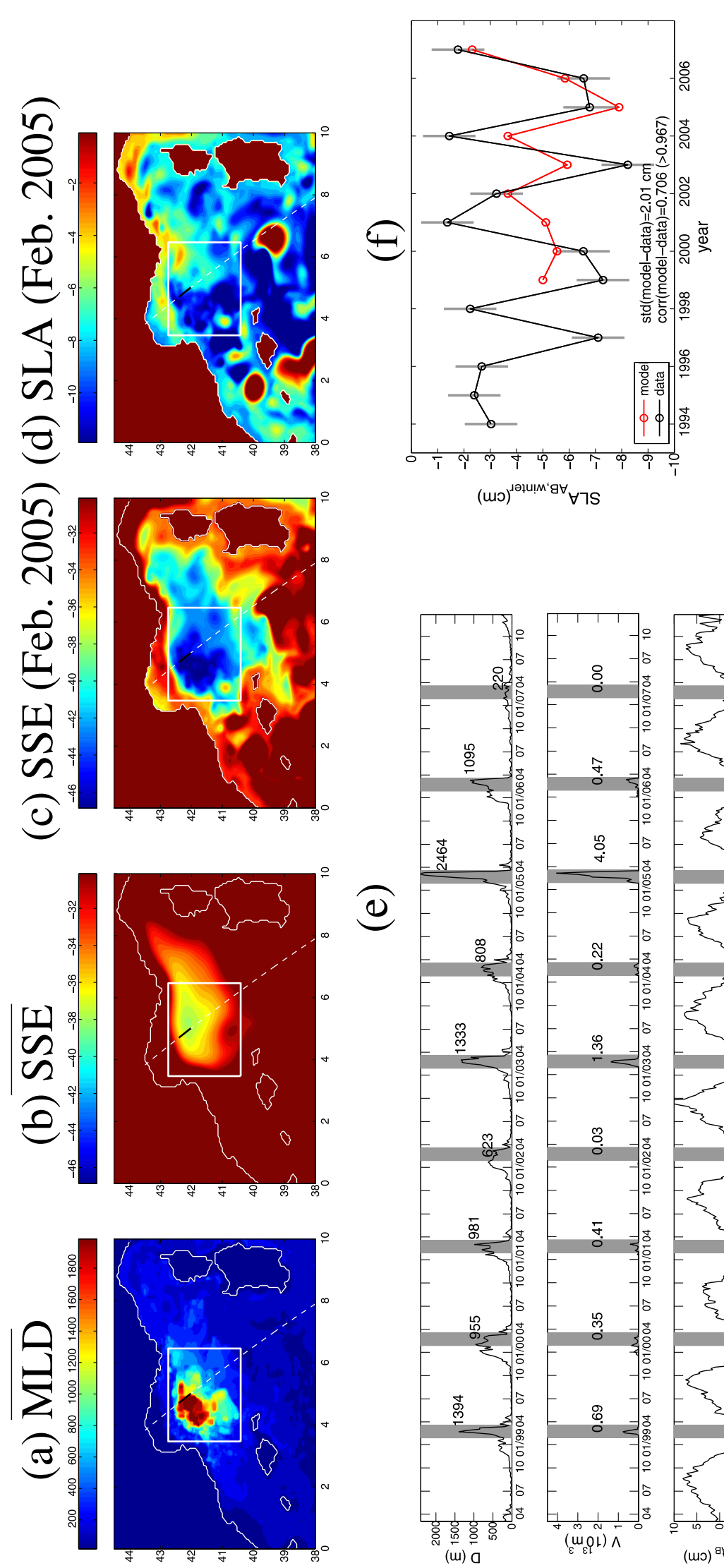

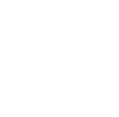

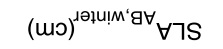
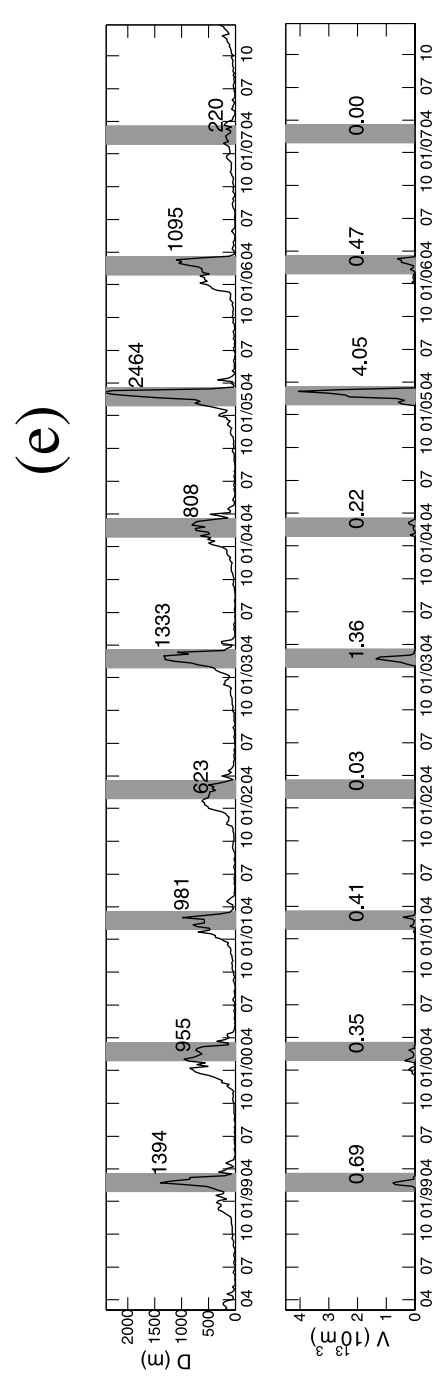
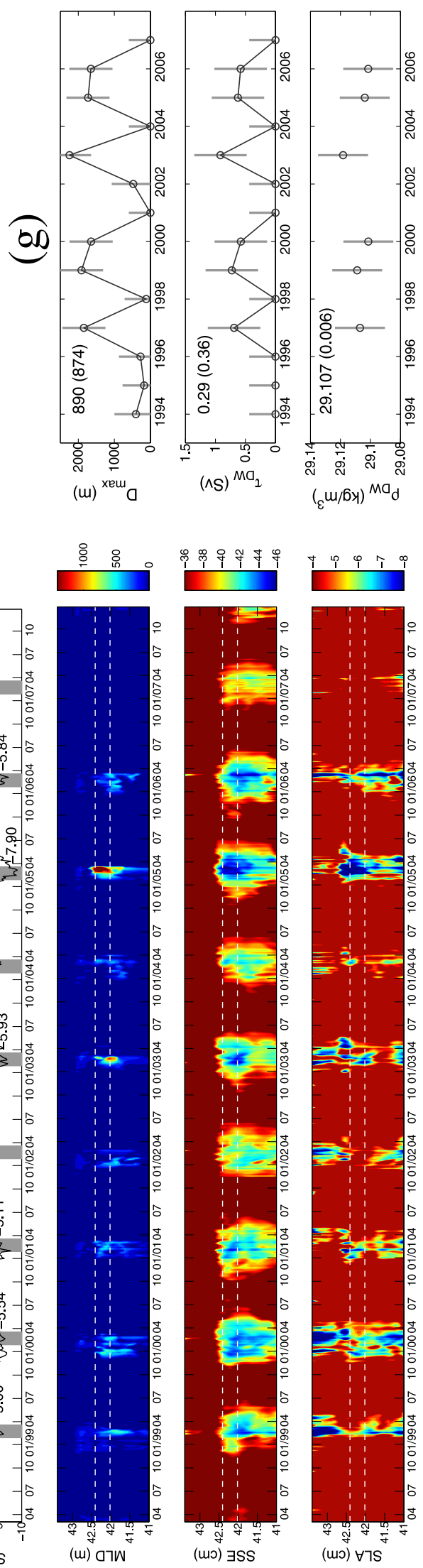

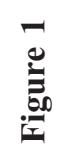


contributes to this lowering: if $D \sim 1 \mathrm{~km}$ is the depth of the mixed layer which undergoes a cooling of $\delta T \sim 0.1^{\circ} \mathrm{C}$ and $\alpha=210^{-4}{ }^{\circ} \mathrm{K}^{-1}$ is the thermal expansion coefficient, a first estimation of the sea surface lowering is given by $\alpha \delta T D \sim$ $2 \mathrm{~cm}$. This $S S E$ decrease is reproduced by the model, as seen in Figures $1 \mathrm{c}$ and $1 \mathrm{~d}$, which shows the SSE and the corresponding $S L A(=S S E-\overline{S S E})$, when $V$ and $D$ are maximum (February 2005).

[15] Track 146 of the altimetry dataset described in Section 2.2 crosses the center of the convection region, where the $M L D$ is maximum and the deepening of the sea surface associated with the convection is the strongest (Figures 1a and 1d). Figure 1e shows the evolution of the modelled MLD, SSE and SLA along track 146 during the 1999-2007 period: the increase of the mixed-layer depth and the deepening of the sea surface due to DC can both be detected along this track in the model. This suggests that the sea surface deepening due to convection can be monitored using altimetry.

[16] We have established an indicator of the intensity of this deepening observed by altimetry data. Section AB is defined as the portion of track 146 that crosses the modelled area of maximum convection and sea surface deepening (Figures 1a and 1d). We compute the $S L A$ averaged over $\mathrm{AB}, S L A_{A B}$, from the model (Figures 1e and S2) and from altimetry data (Figure S2) for the 1999-2007 period. The seasonal variability of the modelled and observed $S L A_{A B}$ are in good agreement, with maximum values in summer and minimum values in winter. The average $S L A_{A B \text {,winter }}$ of $S L A_{A B}$ between the beginning of February and mid-March, i.e., when DC is the strongest, indicates the intensity of the sea surface deepening during the convection event. The interannual variability of $S L A_{A B \text {,winter }}$ is of the same order in the model as in the observations (Figure 1f). In the model, the mean over $1999-2007, \overline{S L A_{A B, \text { winter,model }}}$, is equal to $-5.00 \mathrm{~cm}$ with a standard deviation $\sigma\left(S L A_{A B, \text { winter,model }}\right)$ of $1.62 \mathrm{~cm}$. In the data, $\overline{S L A_{A B, \text { winter,data }}}=-4.80 \mathrm{~cm}$ and $\sigma\left(S L A_{A B \text {,winter,data }}\right)=2.80 \mathrm{~cm}$. The correlation coefficient between the modelled and the observed $S L A_{A B \text {,winter }}$ is 0.71 (SL > 0.967).

[17] The interannual variability of the modelled indicator of winter sea surface deepening, $S L A_{A B, \text { winter }}$, is in good agreement with the altimetry data during the 1999-2007 period. The model can therefore legitimately be used to establish correlations between this indicator and the DC characteristics.

\subsection{Deep Convection Signature on Sea Surface Elevation}

[18] Stronger convection events lead to more intense cyclonic circulation. This suggests that there is a relation- ship between the annual DC characteristics $\left(D_{\max }, \tau_{D W}\right.$ and $\left.\rho_{D W}\right)$ and the indicator of the intensity of the sea surface deepening $\left(S L A_{A B, \text { winter }}\right)$. We use the model results to establish this relationship, performing linear regression analysis between $S L A_{A B \text {,winter }}$ and respectively $D_{\max }, \tau_{D W}$ and $\rho_{D W}$ (Figure S3). We obtain errors $\varepsilon=\sigma$ (model regression) of $244 \mathrm{~m}, 0.24 \mathrm{~Sv}$ and $0.0067 \mathrm{~kg} . \mathrm{m}^{-3}$ and correlation coefficients of $-0.92,-0.81$ and -0.90 , with $\mathrm{SL}>0.99$. The model therefore shows that there is a strong linear relationship between the winter sea surface decrease and the convection characteristics.

\subsection{Deep Convection in the NWMS during the 1994-2007 Period}

[19] Based on these results, we propose and test a method to monitor DC interannual variability and long term evolution using altimetry data.

[20] First, we verify that $S L A_{A B \text {,winter }}$ can be measured accurately enough from space to monitor its variability. If we compare altimetry and tide gauge data to evaluate the precision of the altimetry measurement (see Figure S4), we obtain an error of $1.08 \mathrm{~cm}$ for the winter SLA at the coast during the altimetric period from 1994-2007. Altimetry errors being much larger at the coast than in the deep ocean [Anzenhofer et al., 1999], $1 \mathrm{~cm}$ can be considered as an upper bound of the error on the winter $S L A$ in the convection region. The error on the altimetric signal $\sigma\left(S L A_{A B, \text { winter }}\right)$ is therefore less than $40 \%$ of its variability for $1994-2007$ $(2.56 \mathrm{~cm})$.

[21] We then apply the regression indicators to the whole altimetric series of $S L A_{A B \text {,winter }}$ to estimate the interannual variability of DC in the NWMS during the last 14 years. Results are presented on Figure 1g, together with the associated error bars (see below). There is a strong interannual variability of DC in terms of $D_{\max }$ and $\tau_{D W}$, with average values (respectively $890 \mathrm{~m}$ and $0.29 \mathrm{~Sv}$ ) of the same order as the standard deviations (respectively $874 \mathrm{~m}$ and $0.36 \mathrm{~Sv}) . \rho_{D W}$ varies between $29.10 \mathrm{~kg} \cdot \mathrm{m}^{-3}$ and $29.12 \mathrm{~kg} . \mathrm{m}^{-3}$, corresponding to reported values of WMDW density [Smith et al., 2008]. DC occurs approximately $43 \%$ of the years. Known years with strong convection (1999, 2005 and 2006) or without convection (2007) are correctly captured by this method. Note however that altimetry indicates strong DC for the winter of 1997 while SST data and $Q_{N D J F}$ computed from the NCEP reanalysis dataset show that this winter was warmer than average. We showed in Section 3.1 that $\tau_{D W}$ in the model was correlated with $Q_{N D J F}$, which therefore gives an indication of DC intensity. Considering the period 1994-2007 without taking 1997 into account, the correlation coefficient between $\tau_{D W}$ obtained from the altimetry dataset and $Q_{N D J F}$ is equal to

Figure 1. From altimetry to DC. Figures 1a-1e show spatial characteristics during DC events in the model. (a) Maximum $M L D$ over the 1999-2007 period. (b) $\overline{S S E}$ during the 1999-2007 period. (c) SSE and (d) SLA on the day of maximum convection (February 2005). White box: GoL. White dashed line: track 146. Black line: AB section. (e) time-evolution between 1999 and 2007 of $D, V$ and $S L A_{A B}$, Hoevmuller graphs of the $M L D$, and the SSE and the SLA along track 146. White dashed lines: limits of the AB section. Grey boxes mark the February - mid-March period. Figures 1f $-1 \mathrm{~g}$ show DC monitoring in the NWMS between 1994 and 2007 using altimetry dataset. (f) Yearly evolution of modelled (black) and observed (red) $S L A_{A B \text {,winter }}$ for the 1999-2007 period. Grey bars show the altimetry error. (g) Results obtained by applying the linear relationships established in 4.2 to the 1994-2007 altimetry series. Grey bars show the error due to the regression analysis and the altimetry precision. Mean values and standard deviations (in brackets) are indicated. We did not take into account year 2007 to establish the relationship between $S L A_{A B \text {,winter }}$ and $\rho_{D W}$ since no DW is formed. 
$-0.76(>0.998)$. Thus in most cases satellite altimetry is able to capture correctly the interannual variability of the DC intensity.

[22] Our results are associated with uncertainties due to (1) the numerical oceanic model, (2) the linear regression hypothesis, (3) the altimetry data. Assessing (1) is very difficult due to the lack of data, (2) is given by $\epsilon$ and (3) is given by multiplying the altimetry error $(<\sim 1 \mathrm{~cm})$ by the first-order coefficient of the linear analysis. Adding (2) and (3) we obtain errors of respectively $599 \mathrm{~m}, 0.44 \mathrm{~Sv}$ and $0.017 \mathrm{~kg} \cdot \mathrm{m}^{-3}$. Performing longer simulations using recent high-resolution atmospheric forcing dataset [Herrmann and Somot, 2008] would help to reduce the uncertainty associated with the linear regression. Finally, our method aims to monitor the DC using satellite data, however multiannual in situ observations of the DC would enable more precise calibration and validation of this method potentially leading to more robust estimates of the DC past, present and future variability. Finally, sea level can be changed by barotropic dynamics, thus the inferences from altimetry about deep convection can never be unequivocal.

\section{Conclusion}

[23] The present study is a first step toward space monitoring of DC. Analysis of a high resolution oceanic simulation of the Mediterranean circulation shows that the annual DC characteristics (depth, volume, DW characteristics) and the winter $S S E$ in the DC area are realistically modelled for the 1999-2007 period. Results of this simulation show a strong correlation between DC characteristics and winter SSE at the center of the DC area. Based on these correlations, we propose a method to monitor DC interannual variability and long term evolution using altimetry data. Our method applied to the longest available altimetry series realistically represents DC interannual variability in the NWMS between 1994 and 2007, suggesting it could then be used to monitor its long term evolution. Broadening this method to other DC sites of the world's ocean would be of great interest for establishing new climatic indices of the global thermohaline circulation.

[24] Acknowledgments. OI-SST products used in this study were jointly produced by ENEA-ACS-CLIMMOD and GOS of ISAC-CNR as a part of EU project MFSTEP (EVK3-CT-2002-00075). We thank C. Estournel, S. Somot and R. Morrow for fruitful discussions and careful rereading.

\section{References}

Anzenhofer, M., C. Shum, and M. Rentsh (1999), Coastal altimetry and applications, Tech. Rep. 464, Ohio State Univ., Columbus.

Béranger, K., L. Mortier, and M. Crépon (2005), Seasonal variability of transports through the Gibraltar, Sicily and Corsica straits from a high resolution Mediterranean model, Prog. Oceanogr., 66, 341-364, doi:10.1016/j.pocean.2004.07.013.
Blanke, B., and P. Delecluse (1993), Variability of the tropical Atlantic Ocean simulated by a general circulation model with two different mixed layer physics, J. Phys. Oceanogr., 23, 1363-1388.

Bouffard, J., S. Vignudelli, P. Cipollini, and Y. Ménard (2008), Exploiting the potential of an improved multi-mission altimetric dataset over the coastal ocean, Geophys. Res. Lett., 35, L10601, doi:10.1029/ 2008GL033488

Castellari, S., N. Pinardi, and K. Leaman (2000), Simulation of the water mass formation processes in the Mediterranean Sea: Influence of the time frequency of the atmospheric forcing, J. Geophys. Res., 105, 24,15724,181, doi:10.1029/2000JC900055.

Guarracino, M., S. Marullo, and B. B. Nardelli (2008), 1985-2007: 23 Years of SST (Sea Surface Temperature) in the Mediterranean Sea [CDROM], Ital. Natl. Agency for New Technol. Energy and the Environ., Rome.

Herrmann, M., and S. Somot (2008), Relevance of ERA40 dynamical downscaling for modeling deep convection in the Mediterranean Sea, Geophys. Res. Lett., 35, L04607, doi:10.1029/2007GL032442.

Herrmann, M., S. Somot, F. Sevault, C. Estournel, and M. Déqué (2008), Modeling the deep convection in the northwestern Mediterranean Sea using an eddy-permitting and an eddy-resolving model: Case study of winter 1986-1987, J. Geophys. Res., 113, C04011, doi:10.1029/ 2006JC003991.

Kalnay, E., et al. (1996), The NCEP/NCAR 40-year reanalysis project, Bull. Am. Meteorol. Soc., 77, 437-471.

Lévy, M., L. Mémery, and G. Madec (1998), The onset of a bloom after deep winter convection in the northwestern Mediterranean Sea: Mesoscale process study with a primitive equation model, J. Mar. Syst., 16, 7 21, doi:10.1016/S0924-7963(97)00097-3.

Madec, G., P. Delecluse, M. Imbard, and C. Levy (1998), OPA 8.1 Ocean General Circulation Model Reference Manual, Note Pôle Modél., vol. 11, Inst. Pierre-Simon Laplace, Paris, France.

Marshall, J., and F. Schott (1999), Open-ocean convection: Observations, theory, and models, Rev. Geophys., 37, 1-64.

Mertens, C., and F. Schott (1998), Interannual variability of deep-water formation in the northwestern Mediterranean, J. Phys. Oceanogr., 28, $1410-1424$

Petrenko, A. (2003), Variability of circulation features in the Gulf of Lion NW Mediterranean Sea. Importance of inertial currents, Oceanol. Acta, $26,323-338$

Reid, J. (1979), On the contribution of the Mediterranean Sea outflow to the Norwegian-Greenland Sea, Deep Sea Res., Part I, 26, 1199-1223.

Rixen, M., et al. (2005), The western Mediterranean deep water: A proxy for climat change, Geophys. Res. Lett., 32, L12608, doi:10.1029/ 2005GL022702.

Schroeder, K., A. Ribotti, M. Borghini, R. Sorgente, A. Perilli, and G. P. Gasparini (2008), An extensive western Mediterranean deep water renewal between 2004 and 2006, Geophys. Res. Lett., 35, L18605, doi:10.1029/ 2008 GL035146.

Smith, R. O., H. L. Bryden, and K. Stansfield (2008), Observations of new western Mediterranean deep water formation using Argo floats 20042006, Ocean Sci., 4, 133-149.

Somot, S., F. Sevault, and M. Déqué (2006), Transient climate change scenario simulation of the Mediterranean Sea for the 21st century using a high resolution ocean circulation model, Clim. Dyn., 27, 851-879, doi:10.1007/s00382-006-0167-z.

Tziperman, E., and K. Speer (1994), A study of water mass transformation in the Mediterranean Sea: Analysis of climatological data and a simple three-box model, Dyn. Atmos. Oceans, 21, 53-82.

Uppala, S., et al. (2005), The ERA-40 re-analysis, Q. J. R. Meteorol. Soc., $131,2961-3012$.

K. Béranger, ENSTA, Université Paris 6, CNRS, F-75739 Paris CEDEX 15, France.

J. Bouffard, Laboratoire d'Etudes en Géophysique et Océanographie Spatiales, Université de Toulouse, CNRS, 14 avenue Edouard Belin, F-31400 Toulouse, France.

M. Herrmann, Centre National de Recherches Météorologiques, MétéoFrance, CNRS, 42 avenue Gaspard Coriolis, F-31057 Toulouse CEDEX, France. (marine.herrmann@m4x.org) 